\title{
TURKEY MEAT HYGIENE AND BIOLOGICAL SAFETY ASSESSMENT AFTER DEFROSTING
}

\author{
Anatoly STEKOLNIKOV, Alexander DROZD, Diana ORLOVA, Tamara KALYUZHNAYA, and Yuri KUZNETSOV $\$ \bowtie$ \\ Saint-Petersburg State University of Veterinary Medicine, 5, Chernigovskaya Street, Saint Petersburg 196084, Russia \\ Email: orlova_d@gmail.com; (DORCiD: 0000-0002-8163-8780 \\ Supporting Information
}

\begin{abstract}
Violations of temperature and humidity storage conditions and the intensive development of lactic acid putrefactive microorganisms (micrococcus, yeast, and mold fungi) lead to destructive changes in muscle tissue. The studies established the effect of single and repeated defrosting of turkey meat on the increase in the number of microorganisms that cause spoilage of products and being criteria for meat hygiene and biological safety. As a result of the study, there were no detecting bacteria of the genus Salmonella in a sample of $25 \mathrm{~g}$ of chilled, defrosted, and re-defrosted turkey meat. Also, there was no detecting growth of Listeria monocytogenes and bacteria of the Escherichia coli group in a sample of $1 \mathrm{~g}$ of the product. On the other hand, significant changes were in the dynamics of microbial contamination in terms of the number of mesophilic aerobic and facultative anaerobic microorganisms. Thus, in cooled samples, the total microbial contamination was $3.2 \times 102 \pm 0.2$ colonies of forming units per $1 \mathrm{~g}$ of product. In samples of defrosted turkey meat, this indicator increased 1.8 times and amounted to $5.6 \times 102 \pm 0.4$. However, the obtained value did not exceed the maximum permissible, regulated in the normative and technical documentation. Samples of re-defrosted turkey meat in terms of quantity of Mesophilic Aerobic and Facultative Anaerobic Microorganisms corresponded to $4.7 \times 103 \pm 0.2$, which is 14.5 times higher than in chilled meat samples and 8.4 times higher than in defrosted meat. In addition, the established value of the indicator of microbial contamination in re-defrosting meat exceeded the maximum permissible value established by regulatory enactments. Thus, there is a direct effect of repeated freezing of raw meat on its good quality and safety. Therefore, the solution to such a practical problem as identifying the thermal state of turkey meat acquires a significant role.
\end{abstract}

Keywords: Contamination, Meat hygiene, Meat spoilage, Microbiological control, Storage.

\section{INTRODUCTION}

The most important strategic task of the state is to ensure the food safety of products on the market. For its high nutritional and biological value, Turkey meat is gaining popularity among consumers, but, at the same time, the role and need to control the bio-safety criteria of the raw materials produced increases (Ismail and Joo, 2017; Lauritsen et al., 2019). The slaughter products received and put into circulation from sick poultry, produced with non-observance of veterinary and sanitary requirements, can threaten human health concerning pathogenic and opportunistic microorganisms (Carrasco et al., 2012; Tsigarida et al., 2019). When controlling the products sold, it is necessary to consider the complexity of methods and veterinary and sanitary requirements, regulated by regulatory documents, to the good quality and safety of food products, its identification characteristics at each stage of circulation (Salinas et al. 2014; Orlova and Drozd, 2020).

Demand increase for this product type leads to production intensification and appearance of an effect on the shelves in a wide variety and quantity (Colmenero, 2000). That does not exclude the occurrence of cases of counterfeit turkey meat products or a decrease in its quality (Galarz et al., 2010). However, turkey meat can easily undergo spoilage during storage during trading because of non-compliance with the conditions of its production, temperature violation, storage humidity conditions, or transportation (Bolder, 2007; Voidarou et al., 2011; Chakchouk-Mtibaa et al., 2017). Under improperly storage conditions, turkey meat develops autolytic processes and these processes lead to structural changes in muscle tissue under intensive development of lactic acid, putrefactive microorganisms, micrococci, yeast, molds, etc (Díaz et al., 2008; Luong et al., 2020). As a result, the meat's biochemical composition changes, and protein breakdown products accumulate (Rouger et al., 2017; Saewan et al., 2021). There are a lot of methods and ways for extending poultry meat shelf life that significantly reduce the microflora growth, thereby ensuring the products bio-safety (Patterson and Gibbs, 1973; Mahmoud et al., 2021). Such methods are high pressure freezing, specialized packaging, modified media, etc (Yuste et al., 2002).

In this connection, veterinarians in large companies representing the state and industrial veterinary service in food markets, processing, and refrigeration enterprises, should pay special attention to quality control of raw meat, including the indicators of good quality and biological safety (Chousalkar et al., 2019; Williams et al., 2020). 
The requirements of regulatory and technical documents established the conditions, storage periods, and quality parameters of turkey meat (Yang et al., 2021).

However, to make a profit, unscrupulous manufacturers can use expired turkey meat to manufacture culinary products intended for direct consumption, which, in turn, can cause poisoning in humans and the development of harmful infections (Carroll and Alvarado, 2008; Zhang et al., 2016).

In cases of non-observance veterinary and sanitary rules for raw meat production and circulation and within the framework of state monitoring, it is required to analyze microbiological safety according to the indicators provided by the Customs Union Technical Regulations 034/2013 "On the safety of meat and meat products" (CUTR 034/2013). These indicators are quantity mesophilic aerobic and facultatively anaerobic microorganisms, bacteria of the Escherichia coli group, Staphylococcus aureus, Proteus bacilli, Salmonella, Listeria monocytogenes yeast, and mold, sulfite-reducing clostridia (Cai et al., 2019).

According to the regulatory documents (Prylipko, 2019; Moiseeva and Motovilov, 2020), the shelf life of chilled and frozen turkey meat is advisory and set by the manufacturer. Therefore, to prevent the sale of meat in the trading network that does not meet biological safety requirements, it is necessary to assess it in the conditions of actual product circulation.

The study aimed to establish the effect of a single and repeated defrosting of turkey meat on the increase in the number of microorganisms that cause spoilage of products, as well as being criteria for biological safety.

\section{MATERIALS AND METHODS}

Turkey meat samples for experiments were bought in retail stores in St. Petersburg, Russia. The studies established the effect of single and repeated defrosting of turkey meat on the increase in the number of microorganisms that cause spoilage of products and being criteria for biological safety. A total of 128 samples of turkey meat were studied, including thigh $=26$ pieces, wing $=31$ pieces, drumstick $=18$ pieces, breast $=53$ pieces (Figure 1 ) .

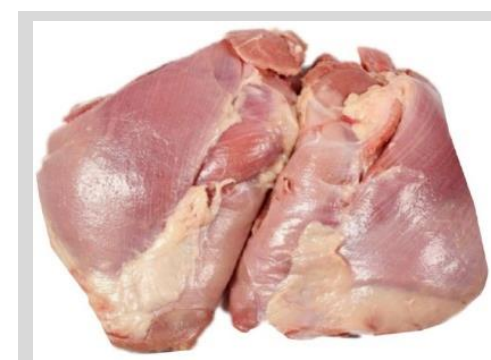

Turkey thigh

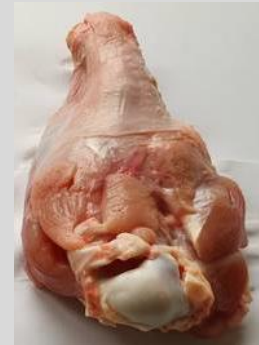

Turkey wing

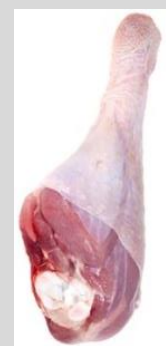

Turkey drumstick

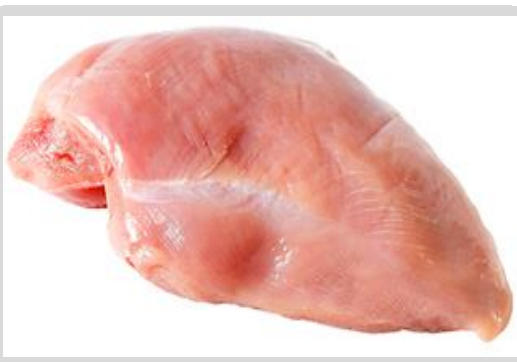

Turkey breast

Figure 1 - The research objects

For identifying bacteria of the genus Salmonella, $25 \mathrm{~g}$ of ground turkey meat was inoculated on a selective enrichment medium - tetrathionate broth (Müller-Kaufmann) in a ratio of 1:10. Then they were incubated at a temperature of $37 \pm 1^{\circ} \mathrm{C}$ for 24 hours. After that, they were sub-cultured on two differential diagnostic media, on XLD-agar and bismuth-sulfite agar. Then they were incubated into a thermostat $\left(37 \pm 1^{\circ} \mathrm{C}\right)$. The cultures were counted after 24 hours, and the final one - after 48 hours (ISO 6579-1:2017).

On XLD-agar, bacteria of the genus Salmonella formed characteristic colonies with a black center and pink colonies with a dark pink center, or yellow colonies with or without blackening. On bismuth-sulfite salmonella agar, black colonies with a metallic sheen were formed. The medium under the colonies was colored, either in the form of greenish colonies with a dark green rim, or colorless colonies without color of the medium.

For identifying Listeria monocytogenes, $25 \mathrm{~g}$ of ground turkey meat was inoculated into Fraser's broth for selective enrichment in a ratio of $1: 9$. Then it was incubated at a temperature of $37 \pm 1^{\circ} \mathrm{C}$ for $48 \mathrm{~h}$. After that, they were subcultured onto differential diagnostic media: ALOA (Listeria Chromogenic Agar Base Acc. to Ottaviani and Agosti), and listeria nutrient agar, incubated in a thermostat $\left(37 \pm 1^{\circ} \mathrm{C}\right)$, the inoculations were counted after 24 hours, and the final one - after 48 hours.

On ALOA, listeria grew in blue-green colonies with an opaque rim. On listeria nutrient agar, listeria formed small grayish-yellow colonies with a black halo (GOST 32031-2012).

Determination of bacteria of the Escherichia coli group was by sowing a crushed sample of $1 \mathrm{~g}$ of turkey meat on Kessler's medium. Crops were incubated at $37 \pm 1^{\circ} \mathrm{C}$ for 24 hours. To consider the growth, a change in the color of the medium and the presence of gas bubbles were noted (GOST 31747-2012).

The quantity of Mesophilic Aerobic and Facultative Anaerobic Microorganisms was determined by inoculation in agar nutrient media. First, a $1 \mathrm{~g}$ weighed portion of the test meat was minced, and a series of successive dilutions were prepared. For inoculation, dilutions of 1:1000, 1:10000, 1:100000 were taken. The inoculation was done in parallel on two Petri dishes from each dilution. For doing this, $1 \mathrm{~mL}$ of material, without touching, was pipetted onto the bottom of the dish. Then the material was distributed over the plate with light rotary movements. After this, 15 minutes later, $20 \mathrm{~mL}$ of 
defrosted and cooled meat were added peptone agar with a temperature of $(45 \pm 1)^{\circ} \mathrm{C}$. The medium was allowed to solidify and incubated upside down at $30^{\circ} \mathrm{C}$ for 72 hours. After that, the crops were recorded, and the colonies were counted. The resulting number of colonies was multiplied by the dilution, and then the arithmetic mean was obtained, which was taken as the value of QMAFAnM in CFU/g (GOST 10444.15-94).

The data obtained from observation checklists were analyzed using SPSS version 21.0 and then exported to Microsoft Excel to calculate the various scores. Descriptive analyses used mean, standard deviation, maxima, and minima for each category. Scores were assessed according to food safety. The two-sample t-test was used to compare microbiological safety Indicators and microbial meat contamination data sets. Comparisons were conducted by fixed-effects analysis of variance. Data were first tested using quantile-quantile plots or the Kolmogorov-Smirnov test, and variance equality was checked using the modified Levene test. Next, Non-normally distributed data sets and those with a sample size less than ten were analyzed using the non-parametric Wilcoxon rank-sum test for two category cases, i.e., sex (male or female), food safety training status (trained or untrained), etc., and the Kruskal-Wallis rank-sum test was used when there were more than two categories. Statistically significant differences were based on $95 \%$ confidence limits, i.e., $\alpha=0.05$ or $\mathrm{p}<0.05$.

\section{RESULTS AND DISCUSSION}

When conducting microbiological studies on the biological safety indicators of turkey meat of various parts of chilled, defrosted, and re-defrosted carcasses, bacteria of the genus Salmonella were not detected in $25 \mathrm{~g}$ of products. Also, in all $25 \mathrm{~g}$ samples, there was no growth of Listeria monocytogenes. In addition, Escherichia coli bacteria had not been detected when inoculating in $1 \mathrm{~g}$ of the product in all studied samples of turkey (Table 1).

Significant changes were in the dynamics of microbial contamination in terms of the number of mesophilic aerobic and facultative anaerobic microorganisms. Thus, in cooled samples, the total microbial contamination was $3.2 \times 10^{2} \pm 0.2$ colonies of forming units per $1 \mathrm{~g}$ of product. In samples of defrosted turkey meat, this indicator increased 1.8 times and amounted to $5.6 \times 10^{2} \pm 0.4$. However, the obtained value did not exceed the maximum permissible, regulated in the normative and technical documentation. Samples of re-defrosted turkey meat in terms of QMAFAnM corresponded to $4.7 \times 10^{3} \pm 0.2$, which is 14.5 times higher than in chilled meat samples and 8.4 times higher than in defrosted meat. In addition, the established value of the indicator of microbial contamination in re-defrosting meat exceeded the maximum permissible value established by regulatory enactments.

Considering the general microbial contamination of parts of turkey carcasses separately, it should be noted that the maximum value of the microbial number was observed in the wing, the minimum - in the breast (Table 2). The higher microbial contamination of wing meat can be explained by the larger surface of this part of the carcasses relative to the volume of muscle tissue than the breast and other parts of the carcasses, which contributes to the more active growth of microflora.

Thus, in chilled wing meat, the value of QMAFAnM was $3.6 \times 10^{2} \pm 0.3$, in defrosted meat $-6.3 \times 10^{2} \pm 0.3$, which is 1.8 times higher than the value of microbial contamination of cooled samples. At the same time, in the repeatedly defrosted turkey wing meat, the microbial number was $5.8 \times 10^{3} \pm 0.1$, which exceeds this indicator in chilled meat by 16.1 times, in defrosted meat, by 9.2 times. On the other hand, the smallest value of the index of microbial contamination was established in chilled breast meat $-2.5 \times 10^{2} \pm 0.4$, which significantly increased in defrosted samples by 1.9 times and amounted to $4.9 \times 10^{2} \pm 0.2$, in re-defrosted samples - in 14.8 times relative to chilled meat and 7.6 times relative to defrosted meat and amounted to $3.7 \times 10^{3} \pm 0.2(p<0.05)$.

Table 1 - Turkey meat microbiological safety Indicators

\begin{tabular}{lccc} 
Indicator & Chilled Turkey Meat & Defrosting turkey meat & Re-defrosted turkey meat \\
\hline Salmonella bacteria & Not detected in 25g & Not detected in 25g & Not detected in 25g \\
Listeria monocytogenes & Not detected in $25 \mathrm{~g}$ & Not detected in $25 \mathrm{~g}$ & Not detected in 25g \\
Escherichia coli bacteria & Not detected in $1 \mathrm{~g}$ & Not detected in $1 \mathrm{~g}$ & Not detected in $1 \mathrm{~g}$ \\
QMAFAnM, CFU/g (average value) & $3.2 \times 10^{2} \pm 0.2$ & $5.6 \times 10^{2} \pm 0.4$ & $4.7 \times 10^{3} \pm 0.2$ \\
M $\pm m, n=128 ; p<0,05$ & & &
\end{tabular}

Table 2 - Turkey meat microbial contamination (QMAFAnM), CFU/g

\begin{tabular}{lccc} 
Part of the carcass & Chilled Turkey Meat & Defrosting turkey meat & Re-defrosted turkey meat \\
\hline Thigh ${ }^{1}$ & $3.4 \times 10^{2} \pm 0.3$ & $5.8 \times 10^{2} \pm 0.4$ & $3.8 \times 10^{3} \pm 0.3$ \\
Drumstick $^{2}$ & $3.3 \times 10^{2} \pm 0.2$ & $5.4 \times 10^{2} \pm 0.1$ & $5.5 \times 10^{3} \pm 0.4$ \\
Breast $^{3}$ & $2.5 \times 10^{2} \pm 0.4$ & $4.9 \times 10^{2} \pm 0.2$ & $3.7 \times 10^{3} \pm 0.2$ \\
Wing $^{4}$ & $3.6 \times 10^{2} \pm 0.3$ & $6.3 \times 10^{2} \pm 0.3$ & $5.8 \times 10^{3} \pm 0.1$ \\
M $\pm m, \mathrm{n}^{1}=26, \mathrm{n}^{2}=18, \mathrm{n}^{3}=53, \mathrm{n}^{4}=31 ; \mathrm{p}<0,05$ & &
\end{tabular}


As a result of studying the microbial contamination of chilled, defrosted, and re-defrosted turkey meat, it was found that single freezing and thawing of meat affects the microbial contamination of products. Still, the obtained values do not exceed the maximum permissible values and consistent with the works of Doulgeraki et al. (2012) and Yu et al. (2021), which describe the positive effect of freezing on extending the shelf life of poultry meat by reducing the activity of microorganisms. However, repeated low-temperature processing of turkey meat and its longer storage contribute to a sharp increase in microbial contamination, including in violation of the requirements for the indicator of the number of mesophilic aerobic and facultative anaerobic microorganisms, which is consistent with the works of Saewan et al. (2021) and Mahmoud et al. (2021). It should be noted that single and double defrosting of turkey meat does not lead to the growth of pathogenic microorganisms that constitute the criteria for biological safety - bacteria of the genus Salmonella, L. monocytogenes, and bacteria of the Escherichia coli group, which is also reflected in the works of Yu et al. (2021) and Mahmoud et al. (2021).

According to Gram, the microbiological study results were also confirmed by microscopy of smears-prints prepared from meat thickness and stained. Looking at least 25 fields of view in smears-prints made from chilled and defrosted meat samples, microorganisms were not detected, or single cocci and/or sticks were recorded, there were no signs of muscle tissue decay. However, in smears-prints from samples of repeatedly defrosted meat in the microscope's field of view, 22 \pm 2 microbial cells and traces of muscle tissue decay in the form of destructively altered muscle fibers were established.

The presence of an increased number of microorganisms detected in smear-prints from re-defrosted meat, as well as the excess in the corresponding samples of the permissible value of QMAFanM, is explained by high proportion of destroyed muscle fibers, disruption of the integrity of the sarcolemma, and going beyond the muscle cells of the sarcoplasm, which together contributes to the development of microflora (Figure 2). The structure of the muscle tissue of defrosted meat is moderately disturbed, single ruptures of muscle fibers are observed, which does not lead to the intensive development of microorganisms (Figure 3). While in chilled meat, while maintaining the integrity of muscle fibers and the absence of destructive changes (Figure 4), the index of microbial contamination meets safety requirements.

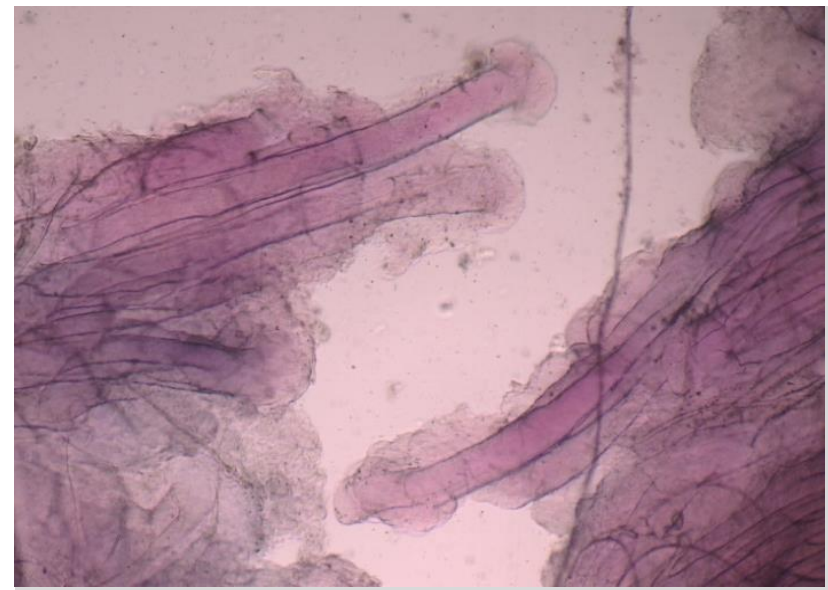

Figure 2 - Micro-picture of the native preparation of repeatedly defrosted turkey meat, magnification $10 \times 4$

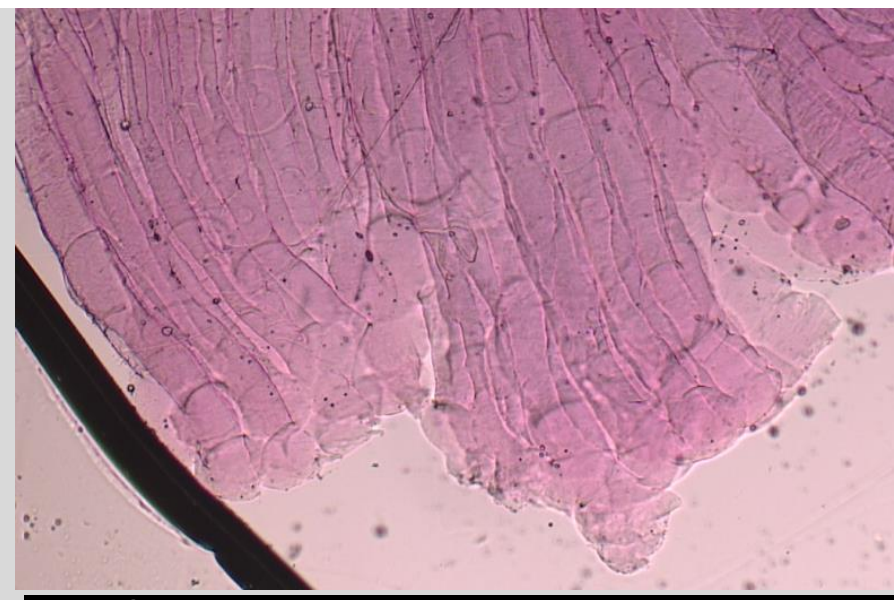

Figure 3 - Micro picture of a native preparation of defrosted turkey meat, magnification $10 \times 4$

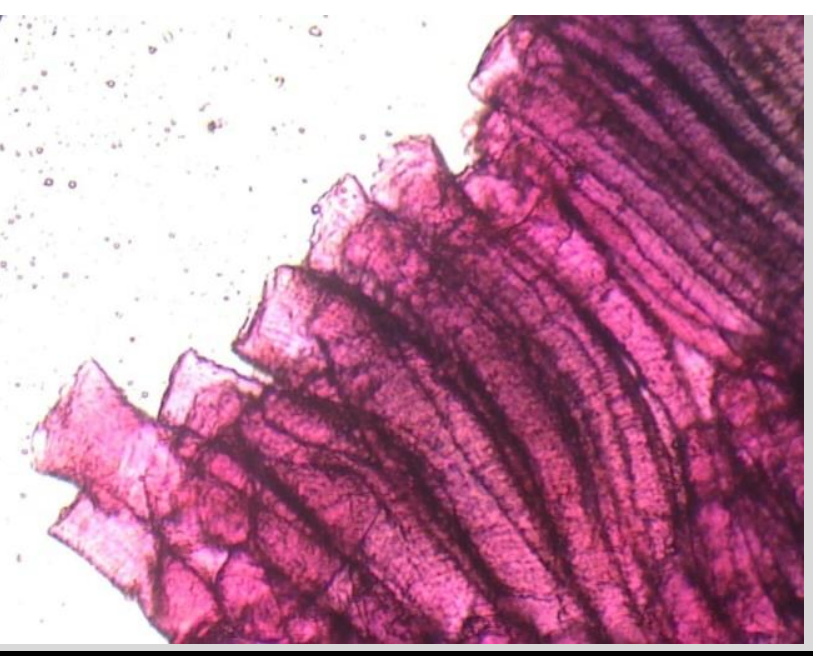

Figure 4 - Micro-picture of a native preparation of chilled turkey meat, magnification 10×4 


\section{CONCLUSION}

From the foregoing, it follows that there is a direct effect of repeated freezing of raw meat on its good quality and safety. Therefore, the solution to such a practical problem as identifying the thermal state of turkey meat acquires a significant role. Carrying out microbiological studies, the significant dynamics of the total microbial contamination by mesophilic aerobic and facultative anaerobic microorganisms should be noted. With repeated freezing and defrosting of meat, there was a sharp increase in microbial cells compared to the original chilled material by 14.5 times. This value exceeds the permissible value established in the regulatory and technical documents by 4.7 times. This phenomenon is provoked by a significant breakdown of muscle tissue elements, thereby creating a more favorable environment for the development of microorganisms and, as a result, the appearance of initial signs of meat spoilage in violation of safety requirements.

\section{DECLARATIONS}

\section{Corresponding author \\ E-mail: orlova_d@gmail.com}

\section{Authors' contribution}

Orlova $\mathrm{D}$, conceived of the presented idea. Kalyuzhnaya $\mathrm{T}$, developed the theory and performed the computations. Stekolnikov A, verified the analytical methods. Kuznetsov $Y$, encouraged Drozd A, to investigate and supervised the findings of this work. All authors discussed the results and contributed to the final manuscript.

\section{Conflict of interests}

The authors have not declared any conflict of interests.

\section{Acknowledgement}

The reported study was funded by RFBR, project number 19-316-90022.

\section{REFERENCES}

Bolder NM (2007). Microbial challenges of poultry meat production. World's Poultry Science Journal, 63(3): 401-411. Google Scholar, https://doi.org/10.1017/S0043933907001535

Cai SHIYU, Worobo RANDYW and Snyder AB (2019). Combined effect of storage condition, surface integrity, and length of shelf life on the growth of listeria monocytogenes and spoilage microbiota on refrigerated ready-to-eat products. Journal of Food Protection, 82(8): 1423-1432. Google Scholar, https://doi.org/10.4315/0362-028X.JFP-18-576

Carrasco E, Morales-Rueda A and García-Gimeno RM (2012). Cross-contamination and recontamination by Salmonella in foods: A review. Food Research International, 45(2): 545-556. Google Scholar, https://doi.org/10.1016/j.foodres.2011.11.004

Carroll CD and Alvarado CZ (2008). Comparison of air and immersion chilling on meat quality and shelf life of marinated broiler breast fillets. Poultry Science, 87(2): 368-372. Google Scholar, https://doi.org/10.3382/ps.2007-00213

Chakchouk-Mtibaa A, Smaoui S, Ktari N, Sellem I, Najah S, Karray-Rebail and Mellouli L (2017). Biopreservative efficacy of bacteriocin BacFL31 in raw ground Turkey meat in terms of microbiological, physicochemical, and sensory qualities. Biocontrol Science, 22(2): 67-77. Google Scholar, https://doi.org/10.4265/bio.22.67

Chousalkar K, Sims S, McWhorter A, Khan S and Sexton M (2019). The effect of sanitizers on microbial levels of chicken meat collected from commercial processing plants. International Journal of Environmental Research and Public Health 16(23): 4807. Google Scholar, https://doi.org/10.3390/ijerph16234807

Colmenero FJ (2000). Relevant factors in strategies for fat reduction in meat products. Trends in Food Science \& Technology, 11(2): 56-66. Google Scholar, https://doi.org/10.1016/S0924-2244(00)00042-X

CUTR 034/2013. Customs Union Technical Regulations. On the safety of meat and meat products. Available at: https://docs.cntd.ru/document/499050564, Link

Díaz P, Nieto G, Garrido MD and Bañón S (2008). Microbial, physical-chemical and sensory spoilage during the refrigerated storage of cooked pork loin processed by the sous vide method. Meat Science, 80(2): 287-92. Google Scholar, https://doi.org/10.1016/j.meatsci.2007.12.002

Doulgeraki Al, Ercolini D, Villani F and Nychas GJE (2012). Spoilage microbiota associated to the storage of raw meat in different conditions. International Journal of Food Microbiology, 157(2), 130-141, Google Scholar, https://doi.org/10.1016/j.ijfoodmicro.2012.05.020

GOST 10444.15-94. Food products. Methods for determination of quantity of mesophilic aerobes and facultative anaerobes. Available at: https://docs.cntd.ru/document/1200022648, Link

GOST 31747-2012. Food products. Methods for detection and quantity determination of coliformes. Available at: https://docs.cntd.ru/document/1200098583, Link

GOST 32031-2012. Food products. Methods for detection of Listeria monocytogenes. Available at: https://docs.cntd.ru/document/1200105310, Link

ISO 6579-1:2017. Microbiology of the food chain - Horizontal method for the detection, enumeration and serotyping of Salmonella - Part 1: Detection of Salmonella spp. Available at: https://www.iso.org/standard/56712.html, Link 
Galarz LA, Fonseca GG and Prentice-Hernández C (2010). Crescimento microbiano em produtos à base de peito de frango durante simulação da cadeia de abastecimento. Ciencia e Tecnologia de Alimentos, 30(4): 870-877. Google Scholar, https://doi.org/10.1590/S0101-20612010000400006

Ismail I and Joo ST. (2017). Poultry meat quality in relation to muscle growth and muscle fiber characteristics. Korean Journal for Food Science of Animal Resources, 37(6): 873-883. Google Scholar, https://doi.org/10.5851/kosfa.2017.37.6.873

Lauritsen CV, Kjeldgaard J, Ingmer H, Bisgaard M and Christensen H (2019). Microbiota encompassing putative spoilage bacteria in retail packaged broiler meat and commercial broiler abattoir. International Journal of Food Microbiology, 300: 14-21. Google Scholar, https://doi.org/10.1016/j.jjfoodmicro.2019.04.003

Luong ND, Coroller L, Zagorec M, Membré JM and Guillou S (2020). Spoilage of chilled fresh meat products during storage: A quantitative analysis of literature data. Microorganisms, 8(8): 1198. Google Scholar, https://doi.org/10.3390/microorganisms8081198

Mahmoud DH, Mahmoud HB, El-Nawawi FAM and Abdel-Naeem HHS (2021). Impact of thawing methods on the bacteriological quality of chicken meat. International Journal of Veterinary Science, 10(3): 214-219. Google Scholar, https://doi.org/10.47278/journal.ijvs/2021.041

Moiseeva N and Motovilov 0 (2020). Quality and Safety Indicators Development of Smoked and Baked Turkey Meat Product. Food Industry, 5(1): 44-49. Google Scholar, https://doi.org/10.29141/2500-1922-2020-5-1-5

Orlova D and Drozd A (2020). Using the histological method to identify the turkey meat thermal state. Advances in Animal and Veterinary Sciences, 8(s2): 12-17. Google Scholar, https://doi.org/10.17582/JOURNAL.AAVS/2020/8.S2.12.17

Patterson JT and Gibbs PA. (1973). Observations on the Microbiology of Cooked Chicken Carcasses. Journal of Applied Bacteriology, 36(4): 689-697. Google Scholar, https://doi.org/10.1111/i.1365-2672.1973.tb04154.x

Prylipko T (2019). Quality Control, Safety Of Raw Meat And Turkey Meat Pate And Justification Of Recipes And Sterilization Regimens. Podilian Bulletin: Agriculture, Engineering, Economics, 1(31): 23-29. Google Scholar, https://doi.org/10.37406/2706-9052-2019-2-3

Rebezov YaM (2019) Safety assessment of products from turkey meat. Actual problems of modern science, technology and education, 10(1): 130-134. Google Scholar, https://www.elibrary.ru/item.asp?id=39537513

Rouger A, Tresse 0 and Zagorec M (2017). Bacterial contaminants of poultry meat: Sources, species, and dynamics. Microorganisms, 5(3): 50. Google Scholar, https://doi.org/10.3390/microorganisms5030050

Saewan SA, Khidhir ZK and Al-Bayati MH (2021). The impact of storage duration and conditions on the formation of biogenic amines and microbial content in poultry meat. Iraqi Journal of Veterinary Sciences, 35(1): 183-188. Google Scholar, https://doi.org/10.33899/ijvs.2020.126584.1346

Salinas Y, Ros-Lis JV, Vivancos JL, Martínez-Máñez R, Aucejo S, Herranz N and Garcia E (2014). A chromogenic sensor array for boiled marinated turkey freshness monitoring. Sensors and Actuators, B: Chemical, 190: 326-333. Google Scholar, https://doi.org/10.1016/j.snb.2013.08.075

Tsigarida E, Gaitis F, Garofalakis G, Papanastasiou D, Marakis G, Mila S and Koutsoumanis K (2019). Evaluation of listeriosis risk related with the consumption of non-prepackaged ready-to-eat (RTE) cooked meat products handled at retail stores in Greece. EFSA Supporting Publications, 16(7): 1677E. Google Scholar, https://doi.org/10.2903/sp.efsa.2019.en-1677

Voidarou C, Vassos D, Rozos G, Alexopoulos A, Plessas S, Tsinas A and Bezirtzoglou E (2011). Microbial challenges of poultry meat production. Anaerobe, 17(6): 341-343. Google Scholar, https://doi.org/10.1016/i.anaerobe.2011.05.018

Williams MS, Ebel ED, Saini G, Nyirabahizi E (2020). Changes in salmonella contamination in meat and poultry since the introduction of the pathogen reduction and hazard analysis and critical control point rule. Journal of Food Protection, 83(10): 1707-1717. Google Scholar, https://doi.org/10.4315/JFP-20-126

Yang X, Zhang Y, Liang R, Zhu L and Luo X (2021). Microbial Spoilage and Formation and Detection of Volatile Odor Compounds in Packaged Chilled Meat: A Review. Food Science, 42(1): 285-293. Link, https://doi.org/10.7506/spkx1002-6630-20200207-046

Yu Z, Joossens M, Kerkhof P and Houf K (2021). Bacterial shifts on broiler carcasses at retail upon frozen storage. International Journal of Food Microbiology, 340, Google Scholar, https://doi.org/10.1016/j.ijfoodmicro.2021.109051

Yuste J, Pla R, Beltran E and Mor-Mur M (2002). High pressure processing at subzero temperature: Effect on spoilage microbiota of poultry. High Pressure Research, 22(3-4): 673-676. Google Scholar, https://doi.org/10.1080/08957950212443

Zhang X, Wang H, Li M, Wu N and Xu X (2016). Near-Freezing Temperature Storage (-2C) for Extension of Shelf Life of Chilled Yellow-Feather Broiler Meat: A Special Breed in Asia. Journal of Food Processing and Preservation, 40(2): $340-347$. Google Scholar, https://doi.org/10.1111/jfpp.12611 